\title{
Announcement/Chronique
}

\section{Call for Papers}

The Canadian Journal of Law and Jurisprudence is planning two special topic issues to appear in 1990 . One will be on Wittgenstein and Legal Theory under the guest editorship of Dennis M. Patterson; the other will be on Collective Rights under the guest editorship of Michael McDonald. Authors with interests in these topics are invited to write to Richard Bronaugh, co-editor, $C J L J$, Department of Philosophy (or Peter Barton, co-editor, Faculty of Law), University of Western Ontario, London, Ontario, Canada N6A 3K7. The editors and guest editors of The Canadian Journal of Law and Jurisprudence are interested in completed essays or in expressions of willingness to submit work in these areas. Tentative deadlines are March 1990 for the Wittgenstein issue and August 1990 for the Collective Rights issue. 